\title{
Gas Lift Technique a Tool to Production Optimization
}

\author{
Okotie Sylvester $^{1}$, Ikporo Bibobra ${ }^{2}$, Ovuema Augustina ${ }^{1}$ \\ ${ }^{1}$ Department of Petroleum and Natural Gas Engineering, Federal University of Petroleum Resources, Effurun, Nigeria \\ ${ }^{2}$ Department of Chemical and Petroleum Engineering, Niger Delta University, Amasoma, Nigeria
}

Email address:

sterz_ok@yahoo.co.uk (O. Sylvester), bblaye3@gmail.com (I. Bibobra), tinaovuema@gmail.com (O. Augustina)

\section{To cite this article:}

Okotie Sylvester, Ikporo Bibobra, Ovuema Augustina. Gas Lift Technique a Tool to Production Optimization. International Journal of Oil, Gas and Coal Engineering. Vol. 3, No. 3, 2015, pp. 41-46. doi: 10.11648/j.ogce.20150303.12

\begin{abstract}
The paramount aim of every oil and gas operator is to minimize both capital and operating costs and more importantly, maximize cumulative oil production in the most cost-effective manner for the entire field. This is to say that a true production optimization requires an operator to take a logical look at the field's production systems from the subsurface to surface facilities. Therefore, when an oil well fails to flow naturally, it requires an assisted lifting system. Gas lift system is one of the few artificial lift methods used to start up a well and/or increase the producing life of oil and gas wells. The principle of Gas lift is by lowering the hydrostatic pressure inside the production tubing through the injection of lighter fluid into the annulus. GT oil field in the Niger Delta was used as case study; it has a production life span of eighteen years. To increase GT production and extend the lifetime of the field, the operator decided to start up an artificial lift project with an aim of optimize its production. To select the best artificial lift method to use, an economic evaluation was carried out using PROSPER for gas lift and a base case (Natural Flow) and then a production forecast with the different scenarios was performed for six years. In technical comparison, PROSPER simulation results shows that Gas lift technique gave a higher production rates when compared with the Base Case (Natural Flow), and in terms of economic comparison by considering factors like: water cut and replacement of failed pump, gas lift system was preferred for proper production optimization techniques. However, gas lift was chosen for GT based on the availability of the readily compressed gas, higher life time expectance and lower installation and operational cost as compared to other artificial lift techniques.
\end{abstract}

Keywords: Gas Lift, Artificial Lift, Natural Flow, Production Optimization, PROSPER, Production Rate, Economic and Sensitivity Analysis

\section{Introduction}

The quantities of reservoir fluids estimated to be commercially recoverable can only be exploited by drilling boreholes (production wells) into the hydrocarbon bearing zones and allowing pressure gradient to force up fluids into these wells by the natural available reservoir pressure and if need be, it is then followed by artificial means or methods. Hence, artificial lift is required on oil wells, when there is insufficient pressure in the reservoir to propel or lift the produced fluids to the surface. Also, artificial lift systems are frequently used in dewatering of gas wells if there is need to sustain production. An extensive overview of artificial lift design considerations was presented by Clegg et al. (1993).

Despite the concern to optimize production, operators in the field need to know the best artificial lift techniques to install in the wells because every operator wants to minimize both capital and operating costs, maximize cumulative oil production in the most cost-effective manner for the entire field. Notwithstanding, a true optimization requires an operator to take a logical look at the field's production systems from the subsurface to surface facilities which implies that production optimization is not an option but a necessity.

Production optimization implies striking a balance between production deliverability of the wells and demand which basically aim at increasing the rate at which a well flows from the reservoir without restriction to the surface storage tank(s). Thus, production optimization through nodal analysis is a way of preparing a well for the production of oil or/and gas from the reservoir to achieve the greatest possible efficiency. Beggs (1991) stated that optimization is directly dependent on some functions. The functions may be a single variable or two or more variables (multivariate optimization). A well is said to be optimized when it is producing at optimum conditions with minimum problems (Bath, 1998). 
Therefore, the essence of drilling and completing a production well is to lift the oil or/and gas from its original location in the reservoir (formation) to the stock tank or sales line.

To determine the optimal gas lift rate, the usual practice is to allocate the lift gas to a well according to a gas-lift performance curve (Nishikiori et al., 1989). Dutta-Roy and Kattapuram (1997) analyzed a gas-lift optimization problem with two wells sharing a common flow line, and pointed out that when flow interactions are significant, nonlinear optimization tools are needed to obtain satisfactory results. Nishikiori et al. (1989) also applied a formal optimization algorithm, a Quasi-Newton method, to the lift gas allocation problem.

This study is basically design to evaluate the efficacy of gas lift as a to tool for production optimization of a known field in the Niger Delta region with Production and systems performance analysis software, PROSPER. Though, there are other artificial lift techniques such as Sucker Rod Pump, Plunger Lift, Progressive Cavity Pump, Hydraulic Pump etc but are not be considered in this study.

Neely et al. (1981) designated some Artificial Lift methods such as: SRP, ESP, HP, GL and studied about the application circumstances, advantages, disadvantages and constraints of each method. The geographical and environmental circumstances as the dominant factors for Artificial Lift selection and also some other subordinate factors such as: reservoir pressure, productivity index, reservoir fluid properties and inflow performance relationship were considered by him (Neely et al., 1981).

There are different key factors that are considered prior to artificial lift installation in the field which include analysis of the individual well's parameters and the operational characteristics of the available lift systems. For the different pumps and lift systems available to the oil and gas industry, there are unique operational/engineering criteria particular to each system, but they all require similar data to properly determine application feasibility. Such as the inflow performance relationship, Liquid production rat, Gas-liquid ratio, Water cut, Well depth, Completion type, Wellbore deviation, Casing and tubing sizes, Power sources, Field location, Solids/sand, Reliability, Efficiency, Environmental impact etc.

Moreover, each of the artificial lift systems has economic and operating limitations that rule out it consideration under certain operating conditions. Some types of lift equipment depending upon the type of installation can have higher initial costs than others. Gas lift can have a high initial cost for a one or two well system where a compressor must be installed. For a large number of wells, gas lift may become economical. Hydraulic pumping becomes less costly where several well can be operated from a central system.

Therefore, knowing the primary required investment value, costs (maintenance, equipment) and technical ability of each Artificial Lift method, Artificial Lift selection was done (Valentine et al., 1988). Clegg (1988) mentioned some economic factors such as: revenue, operational and investment costs as the basis for Artificial Lift selection.

\section{The Problem Definition}

When the reservoir energy is too low for the well to flow, or the production rate desired is greater than the reservoir energy can deliver, it becomes necessary to put the well on some form of artificial lift to provide the energy to bring the fluid to the surface. Hence, one of the challenges faced in lifting the oil and gas from the reservoir via the production tubing to the surface facilities is an unnecessary production decline which poses a serious problem to the oil and gas industry today or inability of the well to flow (expected rate) due to the viscous nature of the fluid. This decline may be as a result of mismanagement of wells, excessive pressure drops along the production system, oversized or undersized tubing, and improper perforation method etc. A change in a single component of the production system may lead to a change in the pressure drop behavior of the other components since the various components are interactive.

In addition, for the fact that artificial lift installed in wells increases the production rate, there are some problems encountered after the installation of these lifting techniques to help recover the column of fluid to the production facilities at the surface. Such as solid/sand handling ability, corrosion/scale handling ability, the stability, number of wells, flowing pressure and temperature limitation, well depth, production rate, flexibility, high GOR, electrical power, space, economics etc. which are factors to consider in the selection prior to the installation of any of the artificial lift techniques. Hence, this study presents a sensitivity analysis on some of these factors for production optimization on gas lift system.

\section{Technical Objectives}

The aim and objectives of every business always culminate to maximize profitability in safe and economic way. Therefore, the objective of the study is to maximize profit from an oil field on a day-to-day basis. This is aimed at:

- Reducing the weight of the column of fluid in the tubing so that the bottomhole pressure of the well is adequate to lift the column and to overcome the resistance of the tubing, pipes and connections. Hence, increase production rates in flowing wells.

- Evaluating the efficacy of gas lift as a tool to increase productivity

- Evaluate the effect of - changing the tubing, water cut, surface choke or subsurface safety valve sizing, skin and Gas-Oil Ratio (GOR),Gravel pack design, etc. on the well production system.

\section{Economics of Artificial Lift Methods}

Once a well has been identify as a candidate for artificial lift, a lot of attention is often paid on the initial capital investment required to install artificial lift. However, the operating costs are normally more important than the capital 
cost when a full life cycle economic analysis is carried out. This was illustrated by J Clegg et al (1993). Thus, it is often viable to invest extra to ensure the best equipment is installed in the well if this will lead to increased revenue (production) and/or reduced operating costs.

When considering the different artificial lift methods under certain operating conditions for installation from their features, each has economic and operating limitations that eliminate it from consideration. (Ayatollahi et al., 2001) stated that the selection of a proper artificial lift method is critical to the long-term profitability of the oil well; a poor choice will lead to low production and high operating costs.

\section{Methodology}

The method adopted for this study was a design of a natural flowing well "base case" and a gas lifted case in PROSPER to ascertain the efficacy of the gas lifted case for production optimization.

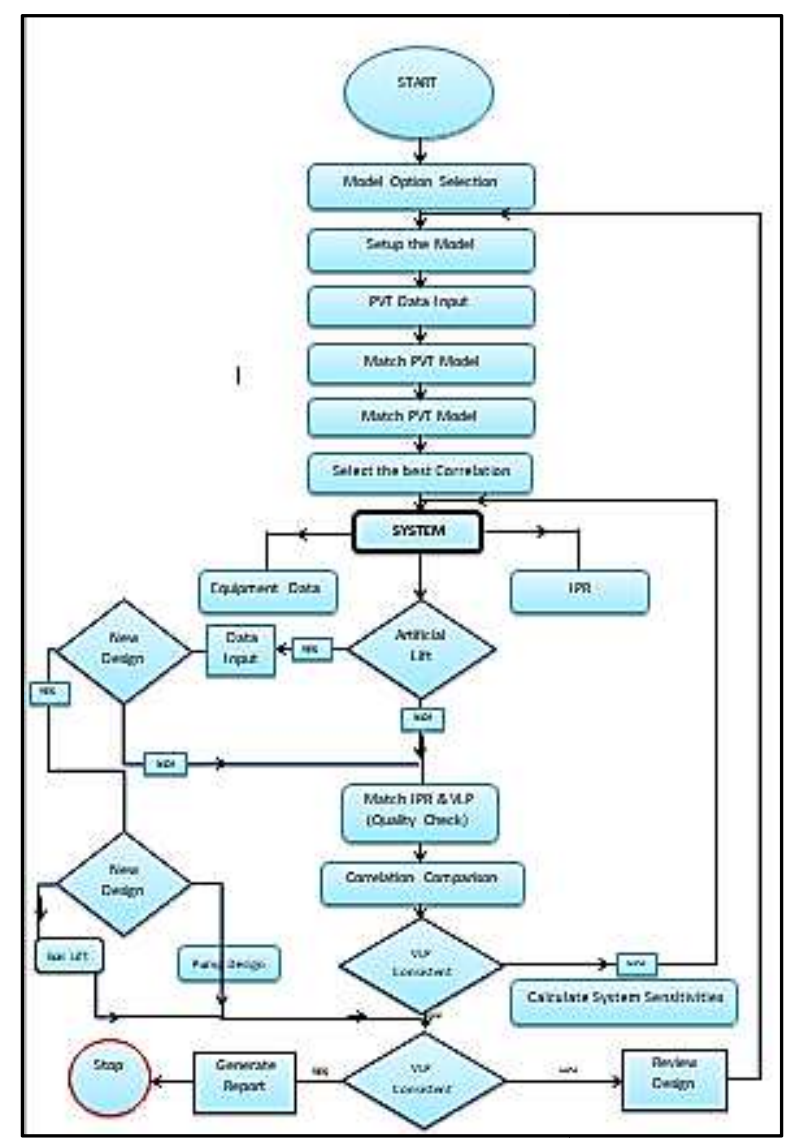

Figure 1. Artificial lift design workflow in PROSPER.

PROSPER is a well performance, design and optimization program for modelling most types of well configurations found in the worldwide oil and gas industry today. It can assist the production or reservoir engineer to predict tubing and pipeline hydraulics and temperatures with accuracy and speed. PROSPER's sensitivity calculation features enable existing well designs to be optimized and the effects of future changes in system parameters to be assessed.
PROSPER is designed to allow building of reliable and consistent well models, with the ability to address each aspect of well bore modelling viz; PVT (fluid characterization), VLP correlations (for calculation of flowline and tubing pressure loss) and IPR (reservoir inflow). By modelling each component of the producing well system, the User can verify each model subsystem by performance matching by tuning the well system model to the real field data (PROSPER User Manual, 2008). Figure 1 represents a workflow of artificial lift design for production optimization in PROSPER.

\section{Results}

The system option was setup in PROSPER for the various scenarios of Gas lift. In this paper, a complete PVT laboratory data was not available hence PVT correlation in Prosper was match to select the best option for GT field. The available PVT data are given in Table 1 and results are presented below. PROSPER uses a non-linear regression to select the best correlations by applying a multiplier (Parameter 1) and a shift (Parameter 2) to each correlation. Glaso correlation was selected for bubble point pressure, solution gas oil ratio and oil formation volume factor while Beggs et al was selected for oil viscosity based on the multiplier and the shift.

Table 1. PVT Data.

\begin{tabular}{ll}
\hline $\mathbf{T}$ & 220 deg F \\
\hline $\mathrm{Pb}$ & $3256 \mathrm{psig}$ \\
$\mathrm{Rs}$ & $820 \mathrm{scf} / \mathrm{STB}$ \\
oil gravity & $37 \mathrm{deg}$ API \\
gas gravity & 0.874 \\
water salinity & $160000 \mathrm{ppm}$ \\
oil viscosity & $0.428 \mathrm{cp}$ \\
Oil FVF & $1.4782 \mathrm{rb} / \mathrm{STB}$ \\
\hline
\end{tabular}

The result of the IPR curve was validated with test data (Table 2) from the field at low and high rate. This was done to ascertain that the test point matches the intercept of the IPR and VLP curves from the mathematical model used to develop the software. Figure 2 shows the inflow performance relationship of WL 14 with skin of 4 which gave an absolute open flow potential of $28593.2 \mathrm{stb} /$ day and productivity index of $11.94 \mathrm{stb} /$ day $/ \mathrm{psi}$.

Table 2. Test Data.

\begin{tabular}{lll}
\hline Parameter & Low rate & High rate \\
\hline WH FP & 930 & 290 \\
WHFT & 134 & 157 \\
WOC & 15 & 15 \\
Liquid rate & 7200 & 12000 \\
Guage depth & 11000 & 11000 \\
Guage pressure & 3940 & 3940 \\
GOR & 820 & 820 \\
\hline
\end{tabular}




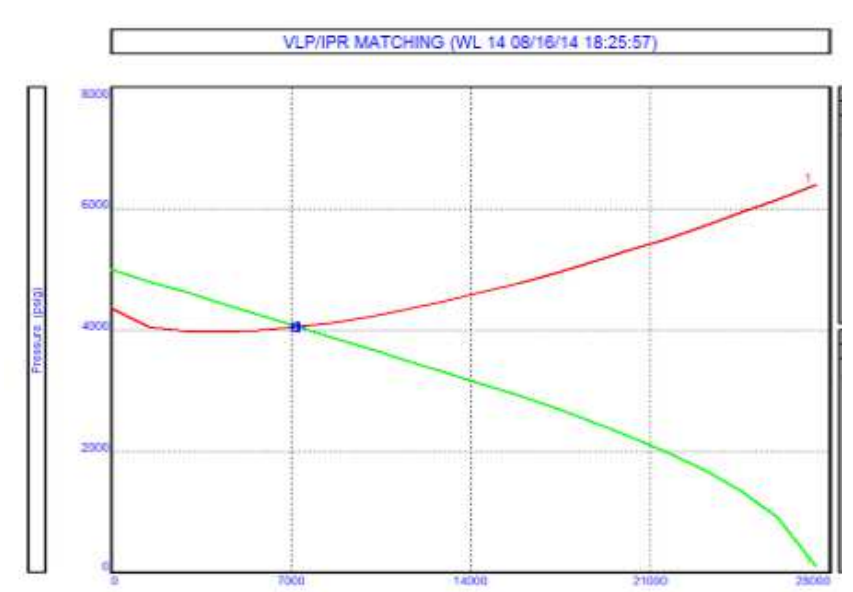

Figure 2. Inflow performance relationship and outflow performance match with test data of WL 14.

In matching the vertical lift performance, the multiphase flow correlation was tuned in order to match the downhole pressure measurement so that the intersect of VLP/IPR will match the production rate as per well test. The available parameters for matching depend on the IPR model in use. For Darcy-IPR model selected for this study, permeability, skin or pressure could be used. Thus, pressure was adjusted to match the IPR and the GOR was check to make sure test data is same with PVT data since the reservoir is still undersaturated.

Table 3. Result from IPR.

\begin{tabular}{llll}
\hline Parameter & Measured & Calculated & \% Difference \\
\hline $\begin{array}{l}\text { Liquid Rate (STB/day } \\
\begin{array}{l}\text { Bottom hole pressure } \\
\text { (psig) }\end{array}\end{array}$ & 7200.0 & 7301.2 & 1.41 \\
\hline
\end{tabular}

\section{Gas Lift Performance Curve}
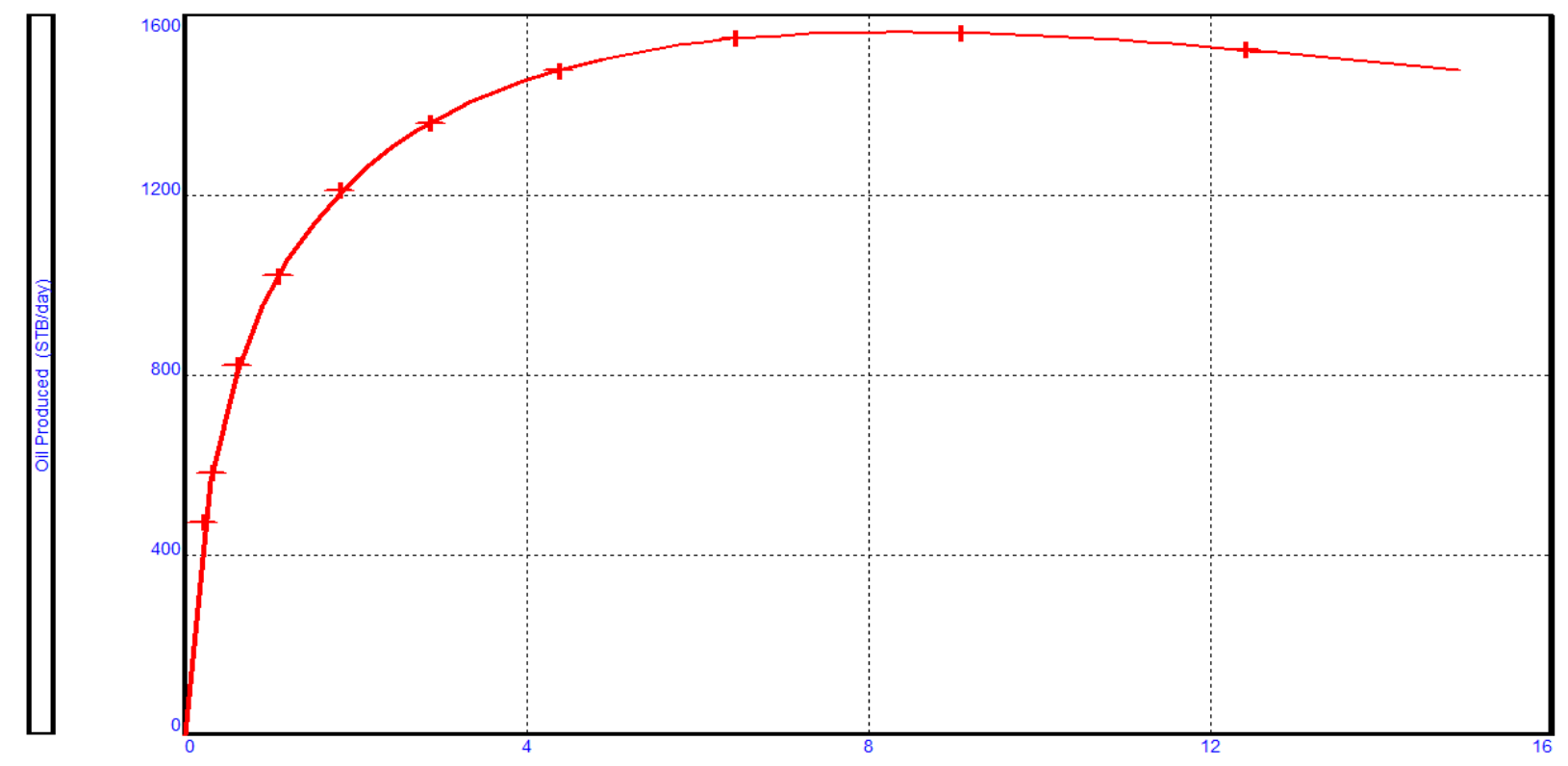

Figure 3. Gas lift performance curve.

The performance curve of a gas lift design; plots the oil rate produced with increased gas injection rates. The greater the amount of gas injected; the lighter will be the fluid column. However a stage reaches in the injection when any further increase in gas injection will increase friction component more than it will decrease gravity component. After this stage any increase in gas injection will decrease production rates. Thus the performance curve will go up and then come down as shown in Figure 3. Looking at the performance curve we see that at a gas lift rate of 5 MMscf/day the oil production is around $1507 \mathrm{stb} /$ day. The maximum oil production of $1579 \mathrm{stb} /$ day occurs for gas lift rate of approximately $8.2 \mathrm{MMscf} /$ day. This represent the optimum gas lift rate for well WL 14. In case the available gas is higher than the optimum gas required, the program will only inject the optimum gas into the well, which is $8.2 \mathrm{MMscf}$ /day in this case.
Table 4. Result of gaslift design rate.

\begin{tabular}{ll}
\hline Parameter & Value \\
\hline GLR Injected & $1054.14 \mathrm{scf} / \mathrm{STB}$ \\
Liquid Rate & $11214.5 \mathrm{STB} /$ day \\
Oil Rate & $2242.9 \mathrm{STB} /$ day \\
VLP Pressure & $3830.81 \mathrm{psig}$ \\
IPR Pressure & $3640.6 \mathrm{psig}$ \\
Standard Deviation & 9.17956 \\
Design Rate & $5 \mathrm{MMscf} /$ day \\
Oil Rate & $2162.3 \mathrm{STB} /$ day \\
\hline
\end{tabular}




\section{Result of Production Forecast of the Natural Flowing and the Gas Wells}

Table 5. Production rate performance.

\begin{tabular}{lllll}
\hline Value & & & \multicolumn{2}{c}{ Total liquid rate (bbl/day) } \\
\hline $\begin{array}{l}\text { Parameter } \\
\text { /year }\end{array}$ & Water-cut & Pressure (psi) & Natural Flow & Gas Lift \\
2008 & 60 & 4246 & 7589.28 & 11814.5 \\
2009 & 65 & 4045 & 7301.2 & 10493.7 \\
2010 & 67 & 3906 & 7049.28 & 9635.5 \\
2011 & 70 & 3878 & 6808.94 & 9216.84 \\
2012 & 71 & 3678 & 6430.1 & 8854.3 \\
2013 & 72 & 3608 & 5945.86 & 8413.94 \\
\hline
\end{tabular}

Figure 4 represents the plot of the natural flowing well and the gas lifted well. It shows an optimized production with the gas with an increase in water cut.

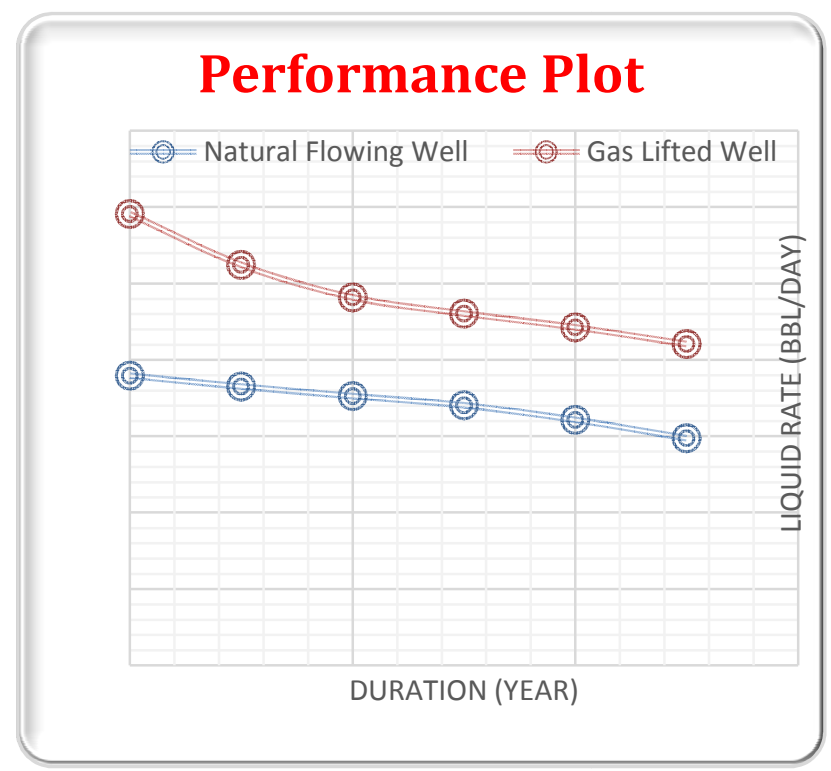

Figure 4. Production performance of base case \& gas lifted well.

\section{Sensitivity Analysis}

For an effective optimization of a system, there is need to carry out sensitivity analysis on the key parameters affecting the productivity of the wells been optimized either via lifting or pumping method. In this study, four parameters were used in the PROSPER sensitivity analysis for production optimization. These are water cut, pressure, tubing diameter and skin. The summary of the sensitivity results are shown in Tables 6-8.

From the sensitivity analysis on the effect of water cut, tubing diameter and skin, the liquid flow rate is highest at water cut $0 \%$, skin of $0 \%$. The value of the liquid flow rate obtained with the water cut and skin are $14773.5 \mathrm{STB} /$ day for 3.958 inches and 20205.8STB/D for 4.892 inches. In reality, this is not possible to achieve because even after success stimulation job to reduce the skin value to zero, there will be possibility of increase in water cut since the well is still produced along with oil. Thus, other options are available for management consideration.

Table 6. Effect of WOC, skin \& tubing diameter on liquid rate.

\begin{tabular}{llll}
\hline WOC & SKIN & TUBING DIA & LIQUID RATE \\
\hline 0 & 0 & 3.958 & 14773.5 \\
40 & 0 & 3.958 & 13530.8 \\
80 & 0 & 3.958 & 9405.2 \\
0 & 2 & 3.958 & 13583.8 \\
0 & 4 & 3.958 & 12533.6 \\
\hline
\end{tabular}

Table 7. Effect of pressure, skin \& tubing diameter on liquid rate.

\begin{tabular}{llll}
\hline SKIN & PRESSURE & TUBING DIAMETER & LIQUID RATE \\
\hline 0 & 2500 & 3.958 & 2328.9 \\
2 & 2500 & 3.958 & 1942.2 \\
4 & 2500 & 3.958 & 1669.5 \\
0 & 3000 & 3.958 & 5615.5 \\
2 & 3000 & 3.958 & 5061.4 \\
4 & 3000 & 3.958 & 4583.5 \\
0 & 4000 & 3.958 & 10493.7 \\
2 & 4000 & 3.958 & 9625.5 \\
4 & 4000 & 3.958 & 8854.3 \\
\hline
\end{tabular}

Table 8. Effect of WOC, skin \& tubing diameter on liquid rate.

\begin{tabular}{llll}
\hline WOC & SKIN & TUBING DIAMETER & LIQUID RATE \\
\hline 0 & 0 & 4.892 & 20205.8 \\
40 & 0 & 4.892 & 18093.6 \\
80 & 0 & 4.892 & 11284.4 \\
80 & 2 & 4.892 & 9409.1 \\
40 & 2 & 4.892 & 15449.4 \\
0 & 2 & 4.892 & 18005.4 \\
40 & 4 & 4.892 & 14240.7 \\
80 & 4 & 4.892 & 8003.1 \\
\hline
\end{tabular}

\section{Economic Analysis}

Before making a final decision on which method of artificial lift to be used, a thorough economic analysis needs to be carried out. It is the profitability of a project that has to be the final decision criteria. This study is still in the evaluation phase, and a full economic analysis giving the NPV of the projects is not available yet. The NPV will give the value of a project through its entire lifetime taking capital costs, operating costs, depreciation and revenues into account. However, the initial cost of the gas lift is analyzed and can give a good indication of the project magnitude. Table 9 shows the capital cost for example, the cost of installation of each project. This involves cost of procurement, construction, engineering, administration and operational cost during installation (rig rate etc.). The amounts do not include company costs such as company personnel, helicopter, catering etc. 
Table 9. Gas-Lift System Cost per Item.

\begin{tabular}{ll}
\hline Items & Cost \$ \\
\hline HP & 3000 \\
Equipments & 50000 \\
Installation & 20000 \\
Running cost/year & 3000000 \\
Maintenance cost/year & 400000 \\
Water Treatment/year & 350000 \\
Barrel of oil & 40 \\
\hline
\end{tabular}

If we assume $\$ 40$ per barrel of crude oil, then the estimated cost for six years is tabulated as shown in Table 10.

Table 10. Gas-lift and ESP Estimated Cost for six years.

\begin{tabular}{ll}
\hline For six years & Gas-lift \\
\hline Item & Cost, $\$$ \\
Horsepower & 1478516 \\
Installation & 70000 \\
Equipment & 300000 \\
Running cost & 18000000 \\
Maintenance & 2400000 \\
Water Treatment & 2100000 \\
Sum & $24,348.516$ \\
\hline
\end{tabular}

Table 11. Estimates of oil revenue.

\begin{tabular}{lll}
\hline Items & Natural Flow & Gas Lift \\
\hline Oil Rate (bbl/6yrs) & 840104.42 & 1090517.74 \\
Revenue (\$/6yrs) & 33604176.78 & 43620709.60 \\
Installation/Operating cost $(\$)$ & 20,500000 & $24,348.516$ \\
Gross Profit (\$) & $13,104,176.78$ & $19,272,193.60$ \\
\hline
\end{tabular}

From the economic analysis on Table 11, we conclude that the cost of running gas lift is higher and this justified it efficacy in the production increase as compared with natural flowing case. The overall performance gave gas lift the best in terms of production increase and gross profit. Also, gas lift may be preferable if an existing gas compressed station is located close to the GT oil field with the availability of gas for injection.

\section{Conclusions}

In an oilfield, the daily available lift gas, often constrained due to facility conditions, this is prone to variation. In addition, operating conditions and handling facilities can dictate compressor deliverability and separator limits during production, while poor allocation of the available lift gas can be economically costly, leading to over-constrained or overdesigned facilities. As such, an optimal lift gas allocation is desirable to ensure that the best possible oil production or profit can be realized. From above discussion, it is obvious that gas lift gave a large increase in production compared to the base case. It is reason to believe that the same difference would be seen in a full field artificial lift campaign. In this study, from a production point of view, the gas lift is a best choice of lifting WL 14.

\section{References}

[1] Bath, England (1998): Introduction to well testing.

[2] B. Neely, F. Gipson, B. Capps, J. Clegg, P. Wilson, "Selection of Artificial Lift method,” Dallas, Texas, 1981, SPE\#1033.

[3] Bath, England (1998): Introduction to well testing.

[4] H. D Beggs, "Production optimization using nodal analysis", oil and gas consultant, International Tulsa, 1991, pp.6, 936,135 .

[5] K. Dutta-Roy and J. Kattapuram, "New approach to gas-lift allocation optimization," in Proceedings of 67th Annual Western Regional Meeting, pp. 685-691, Long Beach, Calif, USA, June 1997.

[6] N. Nishikiori, R. A. Redner, D. R. Doty, and Z. Schmidt, "Improved method for gas lift allocation optimization," in Proceedings of the SPE Annual Technical Conference \& Exhibition (ATCE '89), pp. 105-118, San Antonio, Tex, USA, October 1989. View at Scopus

[7] J. D Clegg, S.M. Bucaram, and N.W. Heln, Jr. "Recommendations and Comparisons for Selecting ArtificialLift Methods." Paper SPE 24834. Journal of Petroleum Technology. December 1993.

[8] J. D. Clegg, "High-rate Artificial Lift," Journal of Petroleum Technology, SPE\#17638.

[9] Petroleum Experts Limited, (2005). "Prosper Single Well System Analysis Version 9.1 User Guide". Scotland.

[10] PROSPER v.10 User Manual, Petroleum Experts. 2008.

[11] S. Ayatollahi, A. Bahadori, and A. Moshfeghian, "Method optimisesAghajari oil field gas lift," Oil and Gas Journal, 2001, vol. 99 , no. 21 , pp. $47-49$. 